\title{
A CONTRIBUIÇÃO DE EDAIR MARIA GÖRSKI PARA A DESCRIÇÃO DE MARCADORES DISCURSIVOS DO PORTUGUÊS FALADO EM FLORIANÓPOLIS
}

\author{
EDAIR MARIA GÖRSKI'S CONTRIBUTION TO DISCOURSE MARKER \\ DESCRIPTION IN BRAZILIAN PORTUGUESE SPOKEN IN FLORIANÓPOLIS
}

\author{
Cláudia Andrea Rost Snichelotto | Lattes | claudiarost@uffs.edu.br \\ Universidade Federal da Fronteira Sul (UFFS)
}

Diane Dal Mago | Lattes | dianedalmago@gmail.com Universidade do Sul de Santa Catarina (UNISUL)

Resumo: Neste artigo reunimos uma compilação de trabalhos orientados pela professora Edair Maria Görski, notadamente que tratam da descrição de marcadores discursivos derivados de diferentes categorias gramaticais, como formas verbais (sabe? e entendeu? olha, veja, vê e quer dizer), reduções frasais (tá?), adjetivos (certo? e bom) e advérbios (bem). A partir da confluência entre a perspectiva teórica da Sociolinguística Variacionista e da Linguística Funcional norte-americana, centramos nossa análise nos resultados dos estudos que investigaram a multifuncionalidade e a variação dos MDs a partir de quatro amostras sincrônicas de fala do português da região Sul do Brasil, provenientes do Banco de Dados do Projeto Interinstitucional VARSUL (Variação Linguística Urbana na Região Sul do Brasil) da cidade de Florianópolis, apesar de certas diferenças metodológicas. De modo geral, as quatro amostras do VARSUL/Florianópolis coletaram 2689 dados de marcadores discursivos, dentre os quais os de base verbal, até este momento, foram os mais investigados nas pesquisas. Os resultados das amostras sincrônicas investigadas apontaram variação e tendência de uso das formas.

Palavras-chave: Marcadores discursivos. Multifuncionalidade. Variação.

Abstract: In this article we gathered a compilation of works advised by professor Edair
Maria Görski, notably those that deal with the description of discourse markers de-
rived from different grammatical categories, such as verbal forms (sabe? and entendeu?,
olha, veja, vê and quer dizer), phrasal reductions (tá?), adjectives (certo? and bom) and 
adverbs (bem). Data analysis was based on the theoretical perspective of Variationist Sociolinguistics and North American Functional Linguistics. Despite certain methodological differences, we centered our analysis on the results of studies that investigated the multifunctionality and variation of DMs from four synchronic samples of speech in Brazilian Portuguese South taken from VARSUL Interinstitutional Project Database (Urban Linguistic Variation in the South of Brazil) in the city of Florianópolis,. In general, the four samples from VARSUL/Florianópolis collected 2689 exemplars of discourse markers, iincluding the verbal ones, which are until now the most investigated in the research. The results of the investigated synchronic samples showed variation and tendency to use the forms.

Keywords: Discourse markers. Multifunctionality. Variation.

\section{Introdução}

As autoras deste artigo têm uma relação acadêmica de longa data com a professora Edair Maria Görski. Inclusive a amizade das autoras começou com os encontros de orientação coordenados por ela na Universidade Federal de Santa Catarina (UFSC). Diane Dal Mago foi aluna de Edair na graduação em Letras, em 1994, depois trabalharam juntas na agência do Projeto VARSUL (Variação Linguística Urbana na Região Sul do Brasil) ${ }^{1}$ em Florianópolis, estendendo-se a parceria para a orientação do mestrado no Programa de Pós-Graduação em Linguística (PPgL) da UFSC. A experiência como membro da equipe auxiliar na agência do VARSUL da Pontifícia Universidade Católica do Rio Grande do Sul (PUCRS) em Porto Alegre foi o mote do encontro de Cláudia Andrea Rost Snichelotto com a professora Edair, no mestrado em Linguística na UFSC. Essa aproximação se deu, primeiramente, pelo mesmo interesse teórico de investigação que a professora Edair na perspectiva da Sociolinguística de inspiração laboviana e, depois, também porque viram, nos marcadores discursivos (doravante MDs), um impulso de pesquisa.

No período de 1995 a 2014, foram coordenados pela Profa. Edair quatro projetos, intitulados "Marcadores discursivos na fala de Santa Catarina - I e II", de 1995 a 2000, e "O percurso de gramaticalização/discursivização de formas de base adverbial e verbal: funções e formas concorrentes I e II”, de 2000 a 2014. Esses projetos resultaram na orientação de 21 pesquisas, dentre as quais 10 relatórios de iniciação científica de estudantes

\footnotetext{
${ }^{1}$ Para informações acerca da constituição do VARSUL, consulte Vandresen (2005), Bisol (2005), Costa (2005) e Vandresen e Coelho (2008) ou acesse a página do Projeto em: http://www.varsul.Org.br.
} 
da graduação em Letras (FREITAG, 1999; 2001; CONSTANTE, 2001; VALLE, 1999, 1998; GÓES, 1998; TAVARES, 1997, 1996; DUARTE, 1997, 1996), 8 dissertações de mestrado (TAVARES, 1999; DAL MAGO, 2001; VALLE, 2001; GASPARINI, 2001; ROST, 2002; FREITAG, 2003; MARTINS, 2003; OLIVEIRA, 2006) e 3 teses de doutorado (TAVARES, 2003; ROST SNICHELOTTO, 2009; VALLE, 2014) do PPgL da UFSC.

Este artigo constitui uma singela homenagem à nossa querida professora-orientadora Edair e reúne uma compilação de sete trabalhos que apresentam resultados consistentes sobre a descrição de MDs provenientes de formas verbais (sabe?, não tem? e entende?, olha, veja e vê, quer dizer), reduções frasais (tá?), adjetivos (certo?, bom) e advérbios (bem). A reunião desses textos também pretende registrar a valiosa contribuição da Profa. Edair não só na orientação de pesquisas descritivas de itens discursivos do português, mas também na formação de recursos humanos na área de Linguística.

É comum a todos os trabalhos o estudo de elementos linguísticos de base verbal, adjetival e adverbial com traços de cognição/percepção/enunciação que, em sua trajetória de mudança, sofrem alteração em sua configuração gramatical, associada a mudanças semânticas-pragmáticas, o que se reflete num continuum multifuncional. As sete pesquisas se apoiam na interface entre a Sociolinguística Variacionista e o Funcionalismo Linguístico norte-americano², conforme Naro (1998), Naro e Braga (2000), Tavares (1999, 2003), Görski et al. (2002, 2003), Görski (2006), Tavares e Görski (2012, 2015), entre outros.

Os estudos aqui reunidos analisam amostras sincrônica e diacrônica do português da região Sul do Brasil. Todavia, neste artigo, centraremos nossa discussão nos resultados das pesquisas que analisaram amostras orais provenientes de entrevistas sociolinguísticas do VARSUL, do município de Florianópolis, em Santa Catarina, porque a amostra base desta localidade tem sido ampliada desde o ano 2000 e pode revelar muito sobre o comportamento dos MDs, embora apresentem diferenças metodológicas na sua constituição.

As questões que colocamos foram: $\mathrm{O}$ que os estudos sobre MDs têm a dizer, em especial, sobre a fala florianopolitana? $\mathrm{O}$ que o controle de fatores extralinguísticos tem a revelar a respeito do uso dos MDs em Florianópolis?

A fim de responder a nossas perguntas, este artigo apresenta quatro partes: na próxima seção, definimos brevemente o que entendemos por $\mathrm{MD}$, dentro do contexto no qual estão inseridos os estudos sumarizados neste artigo. Na seção seguinte, expomos a

\footnotetext{
${ }^{2}$ A vertente norte-americana do Funcionalismo Linguístico recebeu mais recentemente a denominação de teoria baseada no uso (BYBEE, 2010).
} 
multifuncionalidade e a variação dos MDs que subsidiam nossa análise. Na sequência, apresentamos e discutimos os resultados e, por fim, na última seção, propomos as considerações finais.

\section{Marcadores discursivos: breve revisão}

Os MDs são itens linguísticos altamente recorrentes na fala e têm despertado interesse de investigação em diferentes línguas e perspectivas teóricas. Em razão disso, é possível encontrar diferentes termos e definições atribuídas aos MDs, bem como variados materiais e métodos de análise, seja na dimensão sincrônica ou diacrônica (SCHIFRIN, 2003; MASCHLER; SCHIFFRIN, 2015).

No Brasil, Said Ali (1971 [1930] apud URBANO, 1997) foi quem teve visão pioneira ao descrever as expressões de situação - ou MDs - distinguindo os linguísticos (verbais e prosódicos) dos não linguísticos (olhar, riso, expressão corporal). No final da década de 1990, a pesquisa descritiva sobre MDs proliferou com a publicação de Castilho (1989) e Marcuschi (1989), baseada em amostras orais do Projeto NURC (Norma Urbana Linguística Culta). Esses dois trabalhos foram desdobrados por pesquisadores, como, por exemplo, Risso, Silva e Urbano (1996, 2006) e Risso (1999). É, entretanto, o estudo de Silva e Macedo (1996) que avança na descrição dos MDs e na sua correlação com fatores de natureza social. Martelota e Leitão (1996) e Martelotta, Votre e Cezario (1996) analisaram o funcionamento dos MDs em entrevistas realizadas pelo Grupo de Estudos Discurso e Gramática, que também inspiraram inúmeras pesquisas pelo Brasil.

Os MDs provêm de elementos lexicais de variadas categorias gramaticais (cf. SCHIFFRIN, 1987, 2003; MARCUSCHI, 1989; SILVA; MACEDO, 1996; BASÍLIO, 2002), como advérbios (então, bem, apenas e mal), verbos (tá? sabe? entendeu?), pronomes (tal), adjetivos (bom), conjunções (e, mas) (SCHIFFRIN, 1987, 2003; MASCHLER; SCHIFFRIN, 2015), porém, devido à dificuldade de formação de um paradigma homogêneo, tanto parâmetros funcionais (por exemplo, SCHIFFRIN, 1987, 2003; RISSO; SILVA; URBANO, 1996, 2006) quanto formais (por exemplo, DIJK, 1977; FUENTES RODRÍGUEZ, 1987; FRASER, 1999 apud PONS BORDERÍA, 1998) podem ser considerados na sua definição e delimitação. É consenso entre os pesquisadores que os MDs são expressões que relacionam segmentos discursivos (SCHIFFRIN, 1987; FRASER, 1999; TRAUGOTT, 2020) de natureza diversa (cognitiva, expressiva, social e textual) (cf. SCHIFFRIN, 2003; VALLE, 2014).

Neste artigo, consideramos que os MDs são elementos multifuncionais os quais 
"amarram o texto não só enquanto estrutura verbal cognitiva, mas também enquanto estrutura de interação interpessoal” (URBANO, 1997, p. 86). São itens que desempenham um papel comunicativo importante, podendo articular simultaneamente diferentes valores, com graus de maior ou menor proeminência, tanto de caráter textual - estabelecendo elos coesivos entre partes do texto -, como interpessoal - mantendo a interação falante-ouvinte e auxiliando no planejamento da fala (MARCUSCHI, 1989, p. 282). Essa observação do papel comunicativo proeminente dos MDs permite-nos subdividi-los em dois grandes grupos: os intratextuais (ou ideacionais), orientados para o falante e a sua organização textual (quer dizer, bom e bem) e os interpessoais (ou pragmáticos), orientados para o falante e seu ouvinte (sabe, sabes?, não tem?, entende? entendeu?, entendesse?, tá entendendo?, tás entendendo?, olha, veja, vê, tá?, certo?) (CASTILHO, 1989; FREITAG, 2001).

Como se vê, a natureza pragmática da categoria está presente na sua definição, que não se revela como uma tarefa simples, pois envolve um olhar analítico criterioso sobre os contextos de fala em relação às formas e funções desempenhadas.

\subsection{Multifuncionalidade e variação de marcadores discursivos: breve descrição}

Trabalhos variacionistas de orientação funcionalista foram desenvolvidos e orientados pela professora Edair em Santa Catarina. Nessa perspectiva, primeiramente, a partir de uma abordagem funcionalista, as pesquisas descrevem a multifuncionalidade dos itens para captar padrões a partir do uso. Depois, com base em uma abordagem variacionista, tratam os itens como variantes de uma variável linguística (em termos funcionalistas: como camadas de um mesmo domínio funcional), alternantes em um mesmo contexto discursivo. Görski et al. (2003) assinalam que cada variável discursiva se caracteriza como um fenômeno superordenado e gradiente que inclui propriedade $>$ macrofunção $>$ funções, e o recorte da variável pode se dar em cada um dos níveis dessa hierarquia funcional. Para os propósitos do presente artigo, agrupamos os trabalhos segundo a origem da categoria e sempre que possível em ordem cronológica, bem como descrevemos brevemente o comportamento multifuncional dos MDs. São os resultados quali-quantitativos mais gerais que subsidiarão a discussão e a análise da seção 3 .

\subsubsection{Marcadores discursivos de base verbal}

Dal Mago (2001) descreveu o comportamento discursivo da expressão quer dizer a partir do levantamento de dados de 56 entrevistas do VARSUL das cidades de Florianópolis, Blumenau e Chapecó (SC); Porto Alegre e São Borja (RS); Curitiba e 
Londrina (PR). A autora localizou 659 ocorrências do quer dizer, dentre as quais apenas 82 dados são relativos ao $\mathrm{MD}$ na amostra oral investigada. $\mathrm{O}$ ponto central do trabalho diz respeito à multiplicidade de funções desempenhadas pelo item e ao movimento de mudança em seu estatuto categorial. Na literatura linguística, podem ser observados muitos contextos de uso do quer dizer, mas eles não são suficientes para recobrir todos os dados disponíveis na fala.

Com o intuito de delinear a expansão do quer dizer, Dal Mago (2001) delimitou quatro macrofunções para os contextos em que o item ocorre: a macrofunção significa ('significar'), as macrofunções ou seja (retomador, explicativo, esclarecedor e conclusivo) e aliás (atenuador, retificador de conteúdo e de forma) e a macrofunção de planejamento verbal, que abriga os MDs, cuja função específica é a de preenchedor de pausa. Essas macrofunções têm em comum a propriedade de dar sequencialidade ao discurso, funcionando num duplo movimento: anafórico e catafórico. São as funções mais específicas de cada ocorrência em que se insere o item que permitiram delinear o quadro de funcionamento do quer dizer. Nas ocorrências que seguem, pode-se visualizar o funcionamento dessas quatro macrofunções:

1. Eu fazia comboio. Comboio quer dizer tomando conta dos navios mercantes de Belém do Pará, até atracar lá. (DAL MAGO, 2001, p. 10).

2. Nós conhecemos a Itália, de Roma pra cima, digamos assim, de uma maneira bastante - quer dizer, giramos em praticamente toda a Itália do Norte. (DAL MAGO, 2001, p. 76).

3. É, Londrina, a cidade não é assim, boa de se morar, tranquila, quer dizer, já foi mais tranquila, agora já está crescendo, né? (DAL MAGO, 2001, p. 76).

4. Agora hoje você sai, vai pesquisar e pode combater, certo? (pausa) Quer dizer, (pausa), nas matérias que são realmente (pausa), quer dizer (pausa), o negócio da terra, o ar. (DAL MAGO, 2001, p. 78).

Em 1, observam-se duas formas verbais inseparáveis "querer" (auxiliar) e "dizer" (principal), que podem funcionar como sinônimo de significar, havendo a possibilidade de intercambiar a sequência verbal em 1 pela palavra "significa". Em 2, vê-se que o quer dizer tem o papel de reformular e retificar. Já em 3, atua em um contexto cujo papel é de atenuador do discurso, no sentido de abrandar, de diminuir o grau de certeza da infor- 
mação. Na ocorrência 4, quer dizer é um MD que carrega marcas de planejamento verbal, para manter a relação entre os interlocutores.

Mesmo sabendo que os limites para o estabelecimento de uma ou outra função não são estanques, é válido mostrar que, dependendo do contexto de fala, o quer dizer é usado de forma diferenciada, de acordo com as necessidades dos falantes.

Os usos 2 e 3 descritos por Dal Mago (2001) também foram identificados por Bagno (2012, p. 574) no corpus do Nurc-Brasil. Como marcador conversacional, quer dizer é usado para revisar ou confirmar o que se acaba de dizer, tornando-se equivalente a isto é, ou seja, vale dizer etc. (e muito frequentemente pronunciado [kع'dze]).

Os resultados de Dal Mago (2001), em termos de frequência, mostraram que a maior concentração de dados se deu nas macrofunções ou seja e aliás, correspondentes aos articuladores textuais. As funções mais recorrentes também se encontram nesses grupos, que são o esclarecedor e o conclusivo seguidos do preenchedor de pausa e do retificador de conteúdo.

Seguindo a proposta dos projetos de Edair Görski, Valle (2001) efetuou um estudo sobre a multifuncionalidade dos itens sabe?, não tem? e entende?, a partir de uma amostra composta por 36 entrevistas de informantes florianopolitanos, pertencente ao VARSUL. A autora localizou 203 ocorrências de sabe?, 205 de não tem? e 113 de entende?, totalizando 521 dados na amostra oral investigada. Os itens, conforme a autora, compartilham a propriedade interativa de requisitar apoio discursivo, o que permite tratá-los como formas concorrentes dentro de um mesmo domínio. A análise dos contextos de uso revelou que os Requisitos de Apoio Discursivo (RADs) operam em dois níveis: focalizando informações veiculadas no texto e assinalando relações entre partes do texto. Segundo Valle (2001), os dois níveis não se excluem, apenas caminham juntos de maneira superposta. Os fatos de focalização foram divididos da seguinte forma: foco no(s) participante(s); foco na(s) característica(s) do(s) participante(s); foco na avaliação do falante; foco na opinião do falante; foco na situação passada; e foco na situação presente. Exemplificamos a seguir ocorrências dos RADs que focalizam opinião, avaliação e situação presente porque foram as mais recorrentes na amostra de Valle (2001):

5. Agora, o serviço ali é:: um serviço:: brabo, ele é estúpido, sabe? Ele é/ porque é pesa::do, mas sempre uma ajuda a outra, né? (VALLE, 2001, p. 67).

6. Olha, a impressão que eu tenho, sendo eu bancário, o Plano pra mim não:: não resolveu nada, sabe? (est) Apesar que estava tudo, né? numa hora da morte- (VALLE, 2001, p. 68). 
7. Vai fazer dois anos. Porque é:: faz um ano e:: Setembro, outubro, novembro, dezembro, janeiro e fevereiro. É, um ano e cinco meses. (hes) Ela morreu... $\mathrm{Eu}$, assim, conto e não posso contar muito com a família da mãe, entendes?... (est) Que a gente/ que eles sabem assim que eu sou filha adotiva. (VALLE, 2001, p. 69).

Em 5, o julgamento se dá pela predicativa sobre um participante (ele é estúpido). Associado a esse tipo de foco, o RAD pode estar sendo usado pelo falante para enfatizar sua opinião, pedindo a concordância de seu interlocutor, ou, em um sentido inverso, diminuindo a carga assertiva da proposição. Em 6, o que explicita o caráter opinativo daquilo que antecede o RAD é a expressão pra mim. Observe que, em 7, entendes? focaliza situações presentes durativas, parecendo ser usado mais no sentido de checar compreensão.

As relações estabelecidas pelos RADs estão descritas da seguinte forma: especificação, contraste, conclusão, retomada, sequenciação de ações ou de turno, anunciação de complemento, ênfase/atenuação e planejamento verbal. Exemplificamos a seguir ocorrências dos RADs que estabelecem relações de sequenciação, especificação e conclusão, o que vale dizer, relações de caráter textual mais amplo, porque foram as mais recorrentes na amostra de Valle (2001):

8. Foi o que ajudou muito a minha vida pra criar eles, e eles hoje, eu me sinto feliz porque são casados, não são ricos mas são pobres que não me dão trabalho, sabe?, são filhos bons:... não/ não têm vício, o moço, já tenho uma netinha pela parte do filho, de seis anos- (VALLE, 2001, p. 71).

9. Mas ele deu sorte, que ele só queimou por cima, só queimou a pele. Não teve [que]- aquelas queimaduras profundas, entende? Só queimou isso, é, só queimou assim ó, (est) como:: essas coisinhas aqui assim. (VALLE, 2001, p. 66).

10. Mas, enfrento com muito amor, enfrento com toda::, credo, com tudo que eu sinto, assim como se ela fosse uma/ uma moça boa, sabe?... Não me incomodo de não ir a certos lugares porque tenho ela, não saio mesmo quase, é difícil, só uma missa de manhã, enquanto ela fica sozinha, porque a igreja é aqui perto. (VALLE, 2001, p. 74).

Em 8, o RAD assinala o detalhamento daquilo que vem dito antes dele (os filhos e a rotina), introduzindo uma série de construções que especificam aquela sobre a qual o 
item tem escopo. Em 9, entende? antecipa uma conclusão em relação à informação anterior. Em 10, sabe? participa da sequenciação de argumentos feita de forma justaposta, ou seja, sem a presença de conectores, sendo, neste caso, o único elo encadeador explícito da sequenciação.

Os resultados sinalizaram a atuação bidirecional dos RADs e o controle da frequência de uso apontou tanto para situações de variação como para contextos de especialização dos itens.

Valle (2014) confessou, em sua tese de doutorado, que, apesar de anos, durante a iniciação científica (VALLE, 1998, 1999) e o mestrado (VALLE, 2001), estudando MDs, havia desafios ainda maiores a serem enfrentados a respeito do tema. A proposta do novo estudo foi analisar e descrever a multifuncionalidade de sabe? e entende ${ }^{3}$ considerando a atuação de forças semântico-pragmáticas, estilísticas e identitárias em competição. A autora coletou e examinou uma amostra de fala de 30 informantes da comunidade da Barra da Lagoa, em Florianópolis/SC, e encontrou um total de 1.610 ocorrências dos RADs.

Assim como em Valle (2001), Valle (2014) confirmou a propriedade comum a todos os RADs e o comportamento bidirecional dos itens como elementos cujo papel principal é colocar foco na fala, ou seja, têm o intuito de frisar determinadas porções discursivas relacionadas com o interlocutor, e textuais/discursivas, relacionadas com a organização do discurso oral. A classificação dos tipos de foco de Valle (2001) foi revisitada por Valle (2014), que identificou os seguintes tipos na amostra da Barra Lagoa: foco em comentário avaliativo, foco na opinião do falante, foco prospectivo, foco pragmático, foco na busca de informação, foco em situação e em discurso direto reportado. Segundo a autora, a focalização de informações (focalização da situação e em discurso direto reportado) e o grau de identificação do informante com o local mostraram-se relevantes no uso dos itens. Em oposição às formas neutras (sabe?, entende?, entendeu? e tá entendendo?), as formas entendesse?, sabes? e tás entendendo? foram empregadas por aqueles informantes que mais se identificam com a comunidade.

As três ocorrências da sequência, colhidas de Valle (2014), ratificam o comportamento dos MDs de identidade florianopolitana nativa, em contextos de fala em que os informantes demonstram seu apego ao lugar e à cultura local:

11. Aqui eu tô em casa, né? aqui eu me dou com todo mundo, com a população... tendesse? (hes) Sair daqui pra onde? Morar no Centro que é mais movimenta-

\footnotetext{
${ }^{3}$ As macroformas sabe? e entende? recobrem as formas sabe?, sabes?, entende?, entendesse?, sabe? e entende?.
} 
do, que é mais-ah, então aqui não, aqui eu tô mais tranquilo com a família, que (hes) que é uma excelente família, então eu vivo tranqui::lo... tendesse? eu vou ali:: falo com os pes-pescadores, tô aqui vou na minha mãe que mora perto da praia, falo com um amigo, falo com outro, jogo um dominó, um baralho, que fica passando o dia até o outro dia do-dormir pra ir trabalhar, né? (VALLE, 2014, p. 345).

12. Tirava um pedaço, amassava bem, bem, bem, bem em cima da mesa, depois esti- às vez esticava, às vez não, às vez fazia redondinha, broa redondinha, sabe? e às vezes então não, cortava, fazia assim comprido e depois cortava, já ia cortando a broa do tamanho certo, sabes? E: Ah!... ah, depois botava numa forma pra botar no forno pra cozinhar. (VALLE, 2014, p. 66).

13. F: Então esse-tudo isso que nós colhemos e que os meus pais-... que os meus pais colheu, farinha, açúcar, com a graça de Deus, isso tudo não era pra vender, era só pro gasto só da casa (est)... tás entendendo? não se vendia nada, querida... não se vendia nada, era só pro-pro custo de-de [(inint)]

E: $[A]$ única coisa que se vendia era o peixe então?

F: É,era o peixe, mas não tinha pra quem vender.

E: Não?

F: Não.

E: E (hes) e como é que fazia, pescava [(inint)]

F: [Ah, pescava,] fazia um caldo pra comer e outro bocado lá um vizinho comprava um peixinho... tás entendendo? e o outro mais não queria mais. (VALLE, 2014, p. 68).

Novamente, os resultados de Valle (2014) sinalizaram a atuação bidirecional dos RADs e o controle da frequência de uso apontou tanto para situações de variação como para tendências de usos em contextos específicos.

Outras duas pesquisas orientadas pela professora Edair descreveram o comportamento de itens discursivos do português brasileiro: Rost (2002) e Rost Snichelotto (2009). Rost (2002) investigou os MDs derivados de formas verbais olha e veja a partir de dados de fala de 84 informantes do VARSUL das três capitais do Sul do Brasil -

\footnotetext{
${ }^{4}$ As macroformas olha e veja (ROST, 2002) e olha e vê (ROST SNICHELOTTO, 2009) recobrem as variantes: olha $\sim$ olhe $\sim\left[{ }^{\prime} \mathrm{O} \mathrm{j} \mathrm{a}\right] \sim\left[{ }^{\prime} \mathrm{O} \mathrm{j}\right] \sim\left[{ }^{\prime} \mathrm{O}\right]$ e inclusive a construção olha só, e vê envolveu as variantes $v e j a s \sim v e j a \sim v \hat{e} \sim$ vês, inclusive a construção veja bem.
} 
Curitiba, Porto Alegre e Florianópolis. A autora localizou 453 dados do MD olha e 218 do MD veja, totalizando 671 ocorrências na amostra oral investigada. Esses MDs têm em comum a propriedade comum de chamada da atenção do ouvinte que desloca sua referência do contexto situacional para algo do texto do falante. Essa atuação bipartida faz ressaltar o forte valor interpessoal e textual dos itens e permite identificar duas macrofunções (articuladora interacional e articuladora textual), as quais recobrem nove funções específicas (advertência, interjetiva, atenuadora, de planejamento verbal, prefaciadora, retórica, exemplificativa, causal e concessiva) desempenhadas a partir dos contextos brevemente exemplificados a seguir.

14. E: Tânia, me diz uma coisa agora, dentro da educação, o que tu achas da língua portuguesa? O que é falar bem a língua portuguesa pra ti?

F; Olha, pra mim, eu acho assim, que falar bem a língua portuguesa. Olha, eu nem sei te explicar bem [o] a língua portuguesa, porque eu tenho tão pouco tempo de estudo, que eu nem conheço bem a língua portuguesa. (ROST, 2002, p. 6)

15. E: E é um problema sério esse do esgoto. Ainda por cima com essas doenças [agora]. F: [Pois é], E precisava ter, né? porque veja, é dificultoso, uma pessoa quer puxar o esgoto pra rua, não pode. Tem que já fazer fossa e poço morto, que chamam, né? porque não tem encanamento de esgoto. E era tão importante ter. né? (ROST, 2002, p. 10)

Em 14, o item olha, ao chamar a atenção do ouvinte, mantém traços de sentido original no que concerne à percepção visual e introduz um contexto que pode revelar diferentes intenções do falante: ou defesa porque não conhece bem a língua portuguesa; ou tentativa de ganhar tempo para o planejamento e a formulação de sua resposta; ou ainda, olha pode revelar insegurança quanto ao desenvolvimento do tema que lhe foi proposto na pergunta. Em 15, veja, justaposto a "porque", ajuda a articular os argumentos que o falante apresenta com relação aos problemas de esgoto em Curitiba, ao mesmo tempo em que chama a atenção do ouvinte.

De modo geral, os resultados revelaram que o MD olha apresenta fortes características interpessoais como elemento de contato e, paralelamente, parece ocupar posições junto a conectores tipicamente textuais, auxiliando na continuidade do discurso, ao mesmo tempo em que mantém a atenção do ouvinte direcionada para o texto do falante, apresentando, conforme o contexto, características ora mais interpessoais ora mais textuais; 
e o MD veja preserva mais marcas morfossintáticas (número-pessoal e modo-temporal) e tende a coocorrer com pronome na posição estrutural de sujeito, mostrando, portanto, vestígios oracionais. Além disso, seu uso é favorecido em contextos sintaticamente dependentes e em posição medial na frase - características que o tomam mais marcado estruturalmente.

Por fim, o levantamento da frequência de uso das macrofunções e funções discursivas assumidas pelos itens no contexto de uso permitiram observar tanto para situações de variação como para contextos de restrição de uso de olha e veja.

Os resultados de Rost (2002) sinalizaram que algumas questões mereceriam ainda maior atenção, por essa razão, Rost Snichelotto (2009), na sua tese de doutorado, objetivou mapear estágios de mudança de olha e vê (e suas variações) em amostras sincrônicas, compostas por 140 entrevistas do VARSUL de Santa Catarina, e também em uma amostra diacrônica, representada por 17 textos de peças teatrais escritas nos séculos XIX e XX por escritores catarinenses. Na amostra oral investigada, a autora localizou 461 dados do MD olha e 131 do MD vê, totalizando 592 ocorrências. Já na amostra de dados de escrita foram localizadas 66 ocorrências em que predomina o MD olha (olha = 51; vê= 15).

O levantamento na literatura sobre MDs permitiu a identificação do traço comum de percepção que caracteriza olha e vê nas amostras e a identificação de dez contextos de atuação discursiva (de advertência, de opinião, de prefaciação, interjetivo, exemplificativo, de parentetização, causal, adversativo, de atenuação, concessivo). Vejamos algumas ocorrências dos itens:

16. E: Como é que é, como é que consegue conciliar assim do você é vendedora, né? como é que consegue conciliar, assim, tu tens quatro filhos pra cuidar, né? e mais o trabalho de casa e mais o trabalho de fora. Como é que consegue? F: Olha, [não é] não é bem fácil, né? porque, veja bem, quatro filhos mais o de casa, né? eu acho, assim, que é bem < dificultoso>, sabe? pra mim. Tanto que eu tenho tudo eu tenho horário, sabe? pra tudo eu tenho horário, né? Então de manhã eu tenho que ficar em casa porque, né? tem que lavar roupa tem que fazer almoço, né? até [mandar]mandar todo mundo pra escola. Então, geralmente eu saio [depois da] de tarde, né? depois que eu acabo o serviço, né? Então foi esse meio que eu achei pra mim ter [o meu] o meu dinheiro, o meu ganho, né? pra ajudar em casa, foi esse. (ROST SNICHELOTTO, 2009, p. 257). 
A análise funcional apontou ainda o papel da pressão contextual para a emergência de novos usos e a pragmatização do significado de olha e vê. Os enunciados imperativos, inerentemente intersubjetivos, podem vir a ser subjetivizados no curso da mudança de significados de conteúdo, baseados na estrutura argumental, para significados procedurais pragmáticos no nível discursivo (ROST SNICHELOTTO; GÖRSKI, 2011).

Assim como em Rost (2002), em Rost Snichelotto (2009), os resultados indicaram que olha foi a forma mais recorrente nas amostras investigadas em função dos seguintes fatores, entre outros: sincronicamente, há um uso mais generalizado de olha do que de vê, sendo que alguns contextos de atuação discursiva são categóricos para olha; olha se distancia de sua herança verbal em comparação a vê; diacronicamente, o MD olha já aparece em seis diferentes contextos no século XIX, ao passo que vê se manifesta em três contextos no século XX, apenas, com um número bastante reduzido de ocorrências.

Por fim, os diferentes contextos de atuação discursiva de olha e vê são atestados a partir de frequências de uso que apontam tanto para situações de variação como para contextos de restrição de uso.

\subsubsection{Marcadores discursivos de base adjetival e adverbial}

Os dois primeiros trabalhos de Freitag $(1999,2001)$ foram fruto de um projeto de iniciação científica orientado pela professora Edair. No primeiro, analisou a variação de tá? e certo? na fala de 24 informantes de Florianópolis e, no segundo, investigou o comportamento dos MDs tá? e certo? na fala de 72 informantes de Blumenau, Lages e Chapecó do VARSUL de Santa Catarina. A autora localizou 248 dados de tá? e 30 de certo?, totalizando 278 ocorrências nas duas pesquisas. O objetivo foi verificar se a variação de uso de tá? e certo? se constituía como um fenômeno regular na fala catarinense.

Apesar de terem diferenças na sua origem - tá? é de origem verbal e certo? é de origem adjetival -, compartilham propriedades funcionais: testar o canal com o interlocutor, solicitar sua aquiescência, ordenar e reorganizar o fluxo conversacional. Nas ocorrências a seguir, Freitag (2001) mostra que tá? e certo? emergem em contextos considerados incomuns, segundo a perspectiva da gramática tradicional, porque são formas que auxiliam no encadeamento das informações, a seguir exemplificadas:

17. Só porque meus avós moravam perto [de nossa] da nossa casa, e eles não falavam português. Então a gente foi aprender tá? a gente sabia mas que foi praticar o português, foi mesmo quando a gente entrou pra aula, né? (FREITAG, 2001, p. 25).

18. Se você recebe alguém de fora, ela não vai vir diretamente nos bairros, nas fa- 
velas, ela vai ocupar o nosso centro, certo? Claro que [o] o bairro não pode ser deixado, né? deve ser também cuidado, mas a administração não pode olhar especificar, que vai fazer isso e não vai fazer aquilo. (FREITAG, 2001, p. 25).

Os resultados gerais a partir de frequências de uso localizados por Freitag (2001) sinalizam que as quatro cidades catarinenses manifestam comportamentos diferenciados quanto ao uso desses MDs: de um lado, Florianópolis e Blumenau apresentaram maior número de ocorrências do tá? e, de outro, Chapecó e Lages, devido ao baixo número de ocorrências, não demonstraram evidências de restrição de uso de ambas as formas.

A multifuncionalidade dos MDs bom e bem foi pesquisada por Martins (2003), com base na fala de 288 informantes do VARSUL. A autora localizou 754 dados de bom e 118 de bem, totalizando 872 ocorrências na amostra investigada. A análise revelou que os dois itens ocorrem em diferentes contextos que não correspondem a sua origem como adjetivo (bom) e advérbio (bem). Assim, ao adquirirem traços mais discursivos, ambos itens partilham da propriedade de chamada de atenção para a informação no contexto discursivo. Essa propriedade ressalta dois níveis de atuação dos itens, não excludentes mas superpostos, isto é, ora fazem o papel de organizar o texto (macrofunção articuladora textual) e ora marcam a interação entre os interlocutores (macrofunção articuladora interacional). Essas duas macrofunções recobrem uma gama de funções (avaliativa, questionadora, atenuadora, planejamento verbal, prefaciadora, retórica, especificadora, diretiva, enumerativa, sequenciadora, finalizadora e retomadora) desempenhadas a partir dos contextos brevemente exemplificados a seguir.

19. Eu já tenho a casa aqui pra morar, já tenho a casa na praia, o que eu quero mais, né?

E: *Viajar.

F: *É. Ah, viajar. Ah, bom, eu gosto de viajar adoro. Eu disse pra ela que eu fui a Brasília, né? (MARTINS, 2003, p. 41).

20. E: *E daí, ela pretende o que que ela (hes) abrir um consultório? * [De dentista?]

F: Acho que é bem provável, né?

E: Já pensou?

F: Bem, é uma beleza, né? (MARTINS, 2003, p. 41).

21. O poste da frente da minha casa, que é um dos postes mestre [da] da luz, quebrou em três pedaços Ele torceu assim mas foi tudo, não ficou uma árvore 
aqui em pé, nada, foi assim uma destruição aqui. Aqui pra cima. Bom, [aqui] aqui veio [na] [na] no colégio aqui [dá] dá o que, acho que dá dois quilômetros daqui... (MARTINS, 2003, p. 44).

22. E: ${ }^{*}$ Sei. ${ }^{*}$ E na família [da]- das tuas amigas, as pessoas que você convive, né? Aqui em Chapecó (est) (hes) também é assim, ou [você]- a tua família é diferente?

F: Bom, o que eu noto, digamos assim, é que- bom, na família é assim, porque mais amigos assim, digamos assim, ó vejo que nem eu, as minhas primas é assim... (MARTINS, 2003, p. 44).

23. E: $\mathrm{E}\{$ na $\}$ - na sua infância assim, como foi?

F: Bom, a minha infância foi sempre trabalhando, né? Desde os dez anos de idade eu trabalhava com meu pai, [depois]- depois fui trabalhando [por]-por conta própria. Trabalhei dos dez anos até me casar, trabalhava junto com meu pai. (MARTINS, 2003, p. 40).

24. E: E o que que o senhor acha que foi pior, a ditadura do Vargas ou a ditadura militar de sessenta e quatro por aí?

F: Bem, a ditadura do Vargas teve uma coisa, a ditadura do Vargas só nos atingiu nós, os comunistas. (MARTINS, 2003, p. 40).

Em 19 e 20, tanto bom quanto bem exercem o papel de avaliar o que está sendo dito no contexto. Já em 21 e 22, o falante visa a ganhar tempo em seu discurso, ou seja, planejar o que irá dizer. Em 23 e 24, o uso dos MDs dá sequência à pergunta efetuada e também visa à interação entre os interlocutores.

De modo geral, os resultados atestados a partir de frequências de uso de Martins (2003) revelaram que a caracterização dos contextos de uso das formas condicionam a variação entre os itens, embora se verifiquem alguns contextos de restrição de uso de bom e bem.

Mais recentemente, Görski (2020) revisitou parte da amostra analisada por Martins (2003), examinando 72 entrevistas sociolinguísticas de 24 informantes das três capitais do VARSUL, estratificadas quanto à idade (de 25 a 49 anos e acima de 50 anos), ao sexo (masculino e feminino) e à escolaridade (primário, secundário e colegial). A autora categorizou todas as ocorrências de bom e bem (não só como MDs) e reanalisou os contextos de atuação dos MDs sob outros critérios, de modo a captar o espectro da multifuncionalidade dos itens e instâncias de gramaticalização. Foram localizados 247 dados de bom e 29 ocorrências de bem, totalizando 276 MDs nas três capitais. Cabe a ressalva de que, di- 
ferentemente de Martins (2003), que localizou 41 dados de bem e bom em Florianópolis, a reanálise de Görski (2020) identificou 44 ocorrências dos itens na capital catarinense. Os resultados obtidos sinalizam que ambos os MDs compartilham o mesmo domínio funcional de chamada de atenção para a informação numa situação dialógica, embora apresentem especificidades de uso.

Vimos, nesta seção, que os estudos sobre a multifuncionalidade dos MDs originados de formas verbais (quer dizer, sabe?, não tem?, entendeu?, olha, veja, vê, tá?) foram os mais investigados até este momento, ao passo que as pesquisas sobre os MDs originados de adjetivos e advérbios (certo?, bom e bem) ocorreram em menor número. Todas têm como suporte diferentes amostras do corpus do Projeto VARSUL, conforme será detalhado na próxima seção.

\section{Procedimentos metodológicos}

As amostras sincrônicas analisadas pelos trabalhos reunidos neste artigo foram extraídas do VARSUL. A amostra base está transcrita e armazenada eletronicamente e disponível para consulta da comunidade acadêmica nas quatro sedes (UFPR, UFRGS, PUCRS e UFSC). A primeira etapa de constituição do banco foi coletada entre os anos 1988 e 1996 e contém entrevistas com 24 informantes de áreas urbanas representativas de diferentes influências étnicas (açoriana, italiana, alemã, eslava, entre outras), distribuídos igualmente por escolaridade, sexo ${ }^{5}$ e faixa etária. Felizmente, desde o ano 2000, como contribuição de pesquisas de mestrandos e doutorandos, desenvolvidos segundo a perspectiva laboviana, a amostra base das três capitais tem sido acrescida de outras faixas etárias (por exemplo, de 9 a 12 anos e de 15 a 24 anos) e mais um nível de escolaridade (superior), além da coleta de novas regiões desses municípios.

Neste artigo, interessa-nos sumarizar os estudos que investigaram a fala de informantes da capital catarinense, que, além das entrevistas coletadas em áreas mais próximas ao centro, já conta com amostras representativas de regiões mais afastadas da área central, como Ribeirão da Ilha, Costa da Lagoa e Barra da Lagoa ${ }^{6}$.

Dal Mago (2001), Rost (2002), Martins (2003) e Rost Snichelotto (2009) contaram com a amostra de entrevistas de 24 informantes da primeira fase de constituição do VARSUL/Florianópolis estratificadas igualmente por idade ( 25 a 49 anos e mais de 50 anos), sexo (Masculino e Feminino) e escolaridade (até 4 anos $=$ Primário $^{7}$, de 5 a 8 anos $=$ Ginasial e de 9 a 11 anos = Colegial), distribuídos de acordo com o quadro a seguir.

\footnotetext{
${ }^{5} \mathrm{O}$ fator sexo refere-se ao aspecto biológico (masculino e feminino). Não foi feita distinção, à época da constituição da amostra base, entre sexo e gênero.

${ }^{6}$ O detalhamento destas amostras pode ser conferido em Brescancini (2002), Monguilhott (2009) e Valle (2014).

${ }^{7}$ A escolaridade é estratificada e a nomenclatura antiga (primário, ginásio e colegial) substituída nos dias atuais segundo os anos de estudo.
} 
Quadro 1 - Amostra base do VARSUL/Florianópolis

\begin{tabular}{|c|c|c|c|c|c|c|}
\hline \multirow[b]{3}{*}{ Idade $\backslash$ Sexo } & \multicolumn{6}{|c|}{ Escolaridade } \\
\hline & \multicolumn{2}{|c|}{ Primário } & \multicolumn{2}{|c|}{ Ginasial } & \multicolumn{2}{|c|}{ Colegial } \\
\hline & Masc. & Fem. & Masc. & Fem. & Masc. & Fem. \\
\hline 25 a 49 anos & 2 & 2 & 2 & 2 & 2 & 2 \\
\hline Mais de 50 anos & 2 & 2 & 2 & 2 & 2 & 2 \\
\hline Total Parcial & 4 & 4 & 4 & 4 & + & 4 \\
\hline Total & \multicolumn{2}{|c|}{08} & \multicolumn{2}{|c|}{08} & \multicolumn{2}{|c|}{08} \\
\hline \multicolumn{7}{|c|}{ Total de 24 informantes } \\
\hline
\end{tabular}

Fonte: Rost (2002, p. 51).

Além de contar com as 24 entrevistas da primeira fase de constituição do VARSUL, Freitag $(1999,2001)$ e Valle (2001) incluíram, em suas pesquisas, uma amostra suplementar da fala de 12 jovens florianopolitanos, totalizando 36 entrevistas. A amostra está estratificada segundo a faixa de idade ( 15 a 21 anos, 25 a 49 anos e mais de 50 anos), o tempo de escolarização (até 4 anos = Primário, de 5 a 8 anos $=$ Ginasial e de 9 a 11 anos = Colegial) e o sexo (Masculino e Feminino), conforme se visualiza no quadro a seguir.

Quadro 2 - Amostra suplementar 1 do VARSUL/Florianópolis

\begin{tabular}{|c|c|c|c|c|c|c|}
\hline \multirow{3}{*}{ Idade } & \multicolumn{6}{|c|}{ Escolaridade } \\
\hline & \multicolumn{2}{|c|}{ Primário } & \multicolumn{2}{|c|}{ Ginasial } & \multicolumn{2}{|c|}{ Colegial } \\
\hline & Masc. & Fem. & Masc. & Fem. & Masc. & Fem. \\
\hline 15 a 21 anos & 2 & 2 & 2 & 2 & 2 & 2 \\
\hline 25 a 50 anos & 2 & 2 & 2 & 2 & 2 & 2 \\
\hline \multirow[t]{2}{*}{ Mais de 50 anos } & 2 & 2 & 2 & 2 & 2 & 2 \\
\hline & \multicolumn{6}{|c|}{ Total de 36 informantes } \\
\hline
\end{tabular}

Fonte: Valle (2001, p. 57).

Além da inclusão das entrevistas dos jovens de 15 a 21 anos, os estudos de Rost (2002) e Rost Snichelotto (2009 incorporaram 8 informantes à faixa de escolaridade de sua amostra, totalizando 44 informantes distribuídos por faixa de idade ( 15 a 24 anos, 25 a 49 anos e mais de 50 anos), escolaridade (até 4 anos = Primário, de 5 a 8 anos = Ginasial, de 9 a 11 anos = Colegial e mais de 12 anos = Universitária) e sexo (Masculino e Feminino), distribuídos segundo o quadro a seguir. 
Quadro 3 - Amostra suplementar 2 do VARSUL/Florianópolis

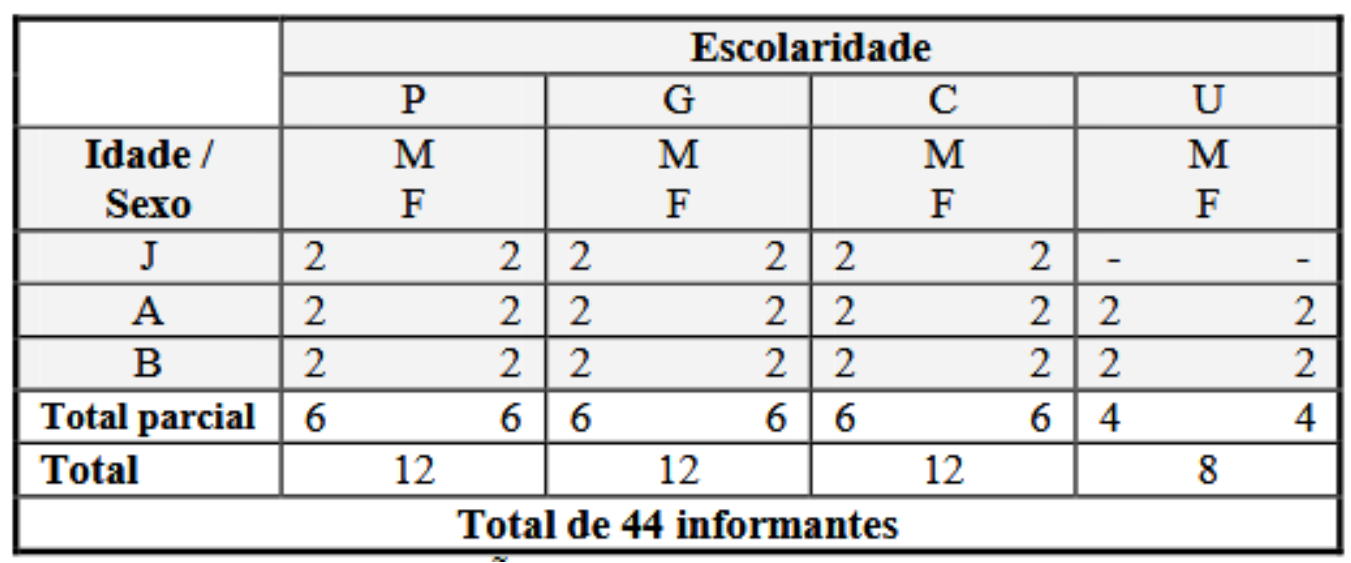

Fonte: Rost Snichelotto (2009, p. 213).

Até aqui as amostras utilizadas pela maior parte dos estudos foram constituídas a partir da coleta aleatória da fala de informantes da área urbana com as mesmas características sociais (idade, sexo e escolaridade), que têm sido consideradas para a realização de pesquisas sociolinguísticas, e do mesmo modelo metodológico de coleta de dados. Durante a coleta, o informante discorre livremente sobre os temas abordados, com o mínimo de interferência linguística do entrevistador, a fim de minimizar a artificialidade da situação e para que as amostras coletadas sejam o mais representativas possível do vernáculo, ou seja, da fala usada em situações naturais de interação face a face nas diferentes localidades (VANDRESEN; COELHO, 2008). Esse modelo homogêneo de constituição das amostras do VARSUL, inserido na primeira onda dos estudos sociolinguísticos, nos moldes de Eckert (2012), permite verificar o reflexo das categorias sociais preestabelecidas na variação e mudança em uma comunidade de fala, bem como garante, em certa medida, a uniformização de dados de vários informantes para comparação posterior, seja dentro de uma mesma comunidade, seja entre comunidades distintas.

A amostra investigada por Valle (2014) apresenta como diferencial a coleta de entrevistas representativas de outra área geográfica da capital catarinense, notadamente a comunidade da Barra da Lagoa, bairro localizado a cerca de $20 \mathrm{~km}$ do centro urbano e situado na região leste de Florianópolis. Segundo a autora, o roteiro da entrevista foi, tanto quanto possível, efetuado por meio de uma conversação mais espontânea. À vista disso, o entrevistador buscava fazer perguntas ao informante relacionadas à identidade local, à história da comunidade e ao turismo na comunidade, a fim de que o uso do vernáculo emergisse na conversa de tal forma que o entrevistado comandasse a interlocução. Esse 
cuidado possibilitou que alguns informantes agissem tão naturalmente que "o momento da entrevista foi interpretado por alguns como uma conversa ou como uma espécie de terapia” (VALLE; GÖRSKI, 2014, p. 102). Embora Valle (2014) não pretenda vincular esse formato de coleta das entrevistas à segunda onda dos estudos sociolinguísticos, nos moldes de Eckert (2012), o método adotado coloca em evidência o significado social das formas em variação em uma determinada comunidade ou grupo social. Outro diferencial dessa amostra é a distribuição dos informantes ${ }^{8}$, que originalmente previa 45 falantes nativos, porém resultou em 30 entrevistas (17 mulheres e 13 homens), distribuídos em idade, sexo e escolaridade, conforme quadro a seguir.

Quadro 4 - Amostra suplementar 3 do VARSUL/Florianópolis

(Amostra Brescancini-Valle).

\begin{tabular}{|c|c|c|c|c|c|c|}
\hline Sexo/gênero & & EMININ & & & SSCULII & \\
\hline & $\begin{array}{c}14 \text { a } 28 \\
\text { anos }\end{array}$ & $\begin{array}{c}33 \text { a } 48 \\
\text { anos }\end{array}$ & $\begin{array}{c}51 \text { a } 83 \\
\text { anos }\end{array}$ & $\begin{array}{c}14 \text { a } 28 \\
\text { anos }\end{array}$ & $\begin{array}{c}33 \text { a } 48 \\
\text { anos }\end{array}$ & $\begin{array}{c}51 \text { a } 83 \\
\text { anos }\end{array}$ \\
\hline Sem escolarização & & & 2 & & & \\
\hline 3 anos & & & & & & 2 \\
\hline 4 anos & & 2 & 3 & & & 1 \\
\hline 5 anos & & & & & & 1 \\
\hline 8 anos & 1 & 3 & & & 2 & \\
\hline 9 anos & 1 & & & 1 & & \\
\hline 10 anos & 1 & & & & & \\
\hline 11 anos & 2 & & & 3 & 3 & \\
\hline $\begin{array}{l}\text { Superior } \\
\text { incompleto }\end{array}$ & 1 & & & & & \\
\hline Superior completo & 1 & & & & & \\
\hline \multirow{2}{*}{ Total parcial } & 7 & 5 & 5 & 4 & 5 & 4 \\
\hline & \multicolumn{3}{|c|}{17} & \multicolumn{3}{|c|}{13} \\
\hline
\end{tabular}

Fonte: Adaptada de Valle (2014, p. 190-191). 
Fica visível até aqui que, embora as quatro amostras do VARSUL sejam constituídas por entrevistas sociolinguísticas, é preciso cautela na análise dos resultados relativos aos fatores sociais. Se a generalização dos resultados das amostras, de um lado, mostra-se impedida em razão da composição de células sociais que foram prejudicadas pela própria configuração, conforme alertou Valle (2014), e da localização geográfica (dois bairros da capital) dos informantes, de outro, a sua convergência pode ser um indicativo acerca da abrangência do uso dos MDs na fala.

Quanto ao tratamento quantitativo dos MDs, os estudos aqui sumarizados submeteram as ocorrências extraídas das entrevistas a testes estatísticos nos programas computacionais VARBRUL 2S (PINTZUK, 1988; SANKOFF, 1988; NARO, 1992) e GoldVarbX (SANKOFF; TAGLIAMONTE; SMITH, 2005). Tendo em vista nossos objetivos, vamos nos valer, predominantemente, das frequências relativas e dos percentuais de uso mais amplos dos MDs.

\section{Resultados e discussão}

Nesta seção, reunimos os resultados mais gerais dos estudos sobre MDs. Cabe a ressalva de que algumas investigações podem apresentar mais ou menos ocorrências de MDs em razão do formato de coleta de dados da amostra, como sinalizamos na seção anterior. Todavia, os resultados poderão apontar tendências de uso de cada forma em Florianópolis.

De modo geral, nas quatro amostras do VARSUL/Florianópolis, foram coletados 2689 dados de MDs. Um volume maior dos itens foi localizado por Valle (2014) em relação às demais pesquisas reunidas neste artigo, isso muito por conta dos estímulos oferecidos ao longo da coleta das entrevistas, conforme visto na seção anterior.

Relativizando-se os resultados em razão da diversidade de amostras e da limitação no número de pesquisas realizadas até este momento, os MDs de base verbal obtiveram, até este momento, 2636 ocorrências, ao passo que os de base adverbial e adjetival apresentaram apenas 66 ocorrências nas pesquisas. Isso pode ser um indicativo da predisposição de formas verbais a evoluírem para a conformação do processo discursivo de estabelecimento de contato e colaboração mútua entre os interlocutores, conforme sugerem Risso, Silva e Urbano (2006, p. 423).

Vejamos, a seguir, o que o controle de fatores extralinguísticos tem a revelar a respeito do uso dos MDs em Florianópolis. 


\subsection{Distribuição dos MDs em Florianópolis por amostra}

Nesta seção, optamos por apresentar os resultados por amostra em razão dos riscos de generalização de amostras heterogêneas. Nossa intenção é, além de verificar a frequência relativa de uso mais amplo, mostrar semelhanças e diferenças nos resultados dos fatores sociais das amostras analisadas e se alguma (e qual) característica social se destaca entre os fenômenos investigados.

Iniciamos com os resultados da amostra base do VARSUL/Florianópolis, que conta com 24 entrevistas de florianopolitanos. As pesquisas que investigaram essa amostra localizaram o total de 197 MDs. Nessa amostra, a maior frequência foi de olha e vê, totalizando 144 dados (ROST, 2002; ROST SNICHELOTTO, 2009). Na sequência, os MDs bem e bom apresentaram forte inibição de uso na fala de florianopolitanos, com apenas 41 dados (MARTINS, 2003), assim como o MD quer dizer com apenas 12 ocorrências (DAL MAGO, 2001) em Florianópolis. Vejamos a distribuição da frequência dos MDs no gráfico abaixo:

Gráfico 1 - Distribuição das ocorrências de MDs da amostra-base do Varsul/ Florianópolis.

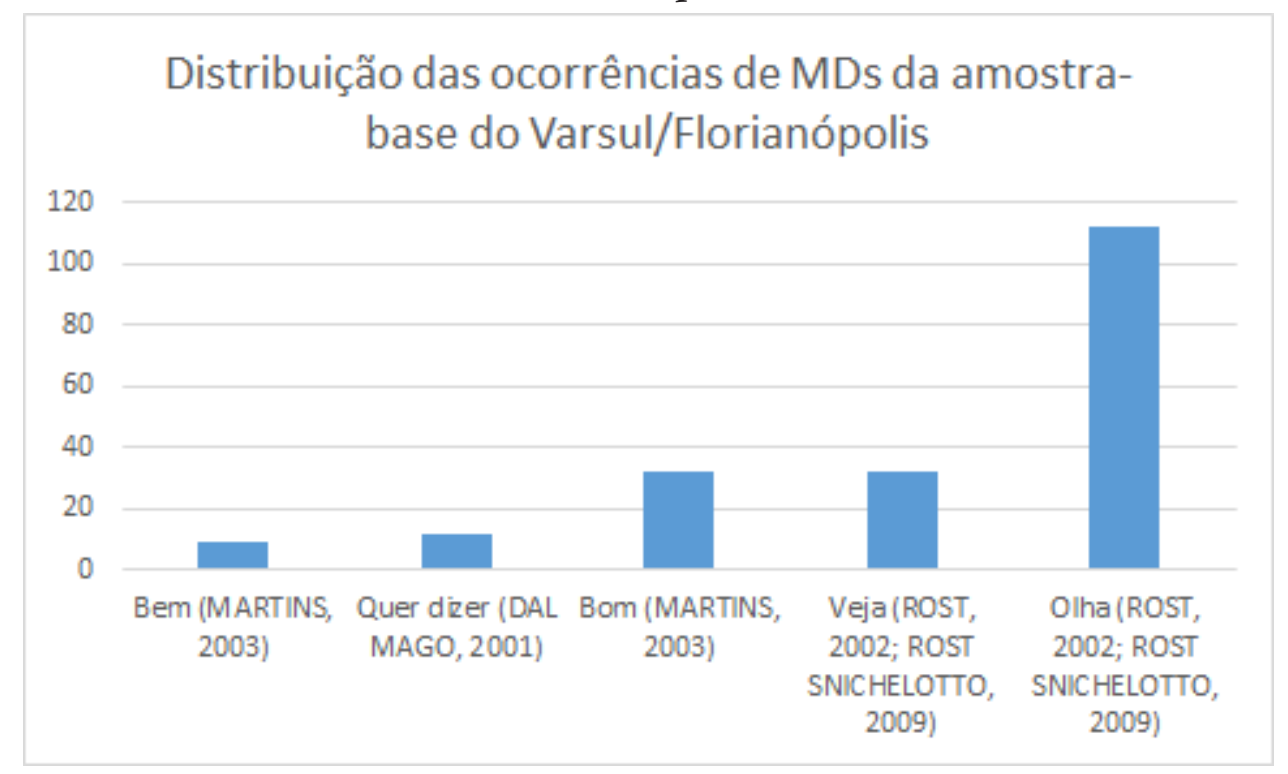

Fonte: Elaboração das autoras (2020).

Nos quatro estudos, foram controlados os fatores sociais idade, sexo e escolaridade cujos resultados gerais reunimos abaixo.

Quanto à variável idade, muitas pesquisas apontam que as formas inovadoras estão relacionadas aos informantes mais jovens. Os resultados revelaram que, na primeira faixa 
de idade (de 25 a 49 anos), concentrou-se o maior número de ocorrências de MDs olha e $v e \hat{e}$, porém, demonstraram o contrário com relação ao uso dos MDs quer dizer, bom e bem. Quanto ao uso preferencial dos itens, a faixa etária acima de 50 anos tenderia ao emprego de olha e bem, enquanto a faixa de 25 a 49 anos privilegiaria o item vê e bom. Embora pareça não haver avaliação social aparente associada a esses MDs, não foi descartada a possibilidade de haver alguma relação com o fator mercado de trabalho.

Quanto à variável sexo, Paiva e Duarte (2003) ressaltam que as mulheres tendem a liderar a mudança quando a nova forma é considerada de prestígio, caso contrário, os homens tomam a ponta do processo de mudança. Silva e Macedo (1996) tinham como hipótese que as mulheres empregariam mais MDs em geral, o que foi confirmado, tendo em vista que as mulheres usaram de modo mais recorrente os MDs (bom, olha). De modo contrário, tendo em vista a crença de que possa haver prestígio social envolvido no uso desses MDs, a expectativa era que as mulheres empregariam menos os MDs em suas falas do que os homens. Porém, Coulthard (1991) alerta que a necessidade de ser polido não é determinada pelo sexo, mas depende das relações que se estabelecem face a face. Os resultados de Dal Mago (2001) revelaram pouca diferença entre homens e mulheres e os de Rost (2002) e Rost Snichelotto (2009) mostraram que os homens fazem um pouco mais uso dos MDs do que as mulheres em Florianópolis, o que contrariou a hipótese de Martins (2003).

Quanto à variável escolaridade, estudos variacionistas têm apontado efeitos interessantes sobre o uso de formas discursivas no PB. Citam-se, por exemplo, as pesquisas provenientes de amostras do VARSUL, como a de Görski e Freitag (2006). Silva e Macedo (1996) postularam que os MDs bom, olha e ah diminuiriam com o aumento da escolaridade, porém esses itens não manifestaram diferenças neste sentido. Martelotta e Leitão (1998), por sua vez, verificaram que os MDs quer dizer, entendeu?, tá? e agora tendem a ocorrer entre os mais escolarizados. $\mathrm{O}$ autor argumenta que o uso desses elementos discursivos entre os que possuem um grau mais elevado de escolaridade está relacionado às marcas de interação presentes nesses elementos. Dessa forma, a expectativa era que quanto maior o nível de escolaridade mais haveria uso de MD. Os resultados de Dal Mago (2001) e Martins (2003) apontaram que quanto maior a escolarização maior o uso de MDs. Rost (2002) e Rost Snichelotto (2009) observaram que as três faixas de escolaridade empregam de modo equilibrado os MDs.

$\mathrm{O}$ que conseguimos resumir até aqui a respeito do comportamento dos MDs quer dizer, olha e vê, bom e bem na amostra base do VARSUL/Florianópolis? (i) os mais jovens 
usam mais olha e vê, e os mais velhos empregam mais quer dizer, bom e bem; (ii) os homens usam mais olha e vê, as mulheres empregam mais bom e bem; homens e mulheres demonstram pouca diferença em relação ao emprego de quer dizer; (iii) os mais escolarizados usam mais quer dizer, bom e bem; os três níveis de escolarização empregam de modo equilibrado olha e vê.

Passamos aos resultados da amostra suplementar 1 do VARSUL/Florianópolis, que conta com 36 entrevistas de florianopolitanos. As pesquisas que investigaram essa amostra localizaram o total de 657 MDs. A maior frequência foi dos RADs sabe?, não tem? e entende? com 521 dados (VALLE, 2001), seguido dos MDs tá? e certo? com apenas 136 ocorrências (FREITAG, 2001) em Florianópolis. Vejamos a distribuição da frequência dos MDs no gráfico abaixo:

Gráfico 2 - Distribuição das ocorrências de MDs da amostra suplementar 1 do Varsul/ Florianópolis.

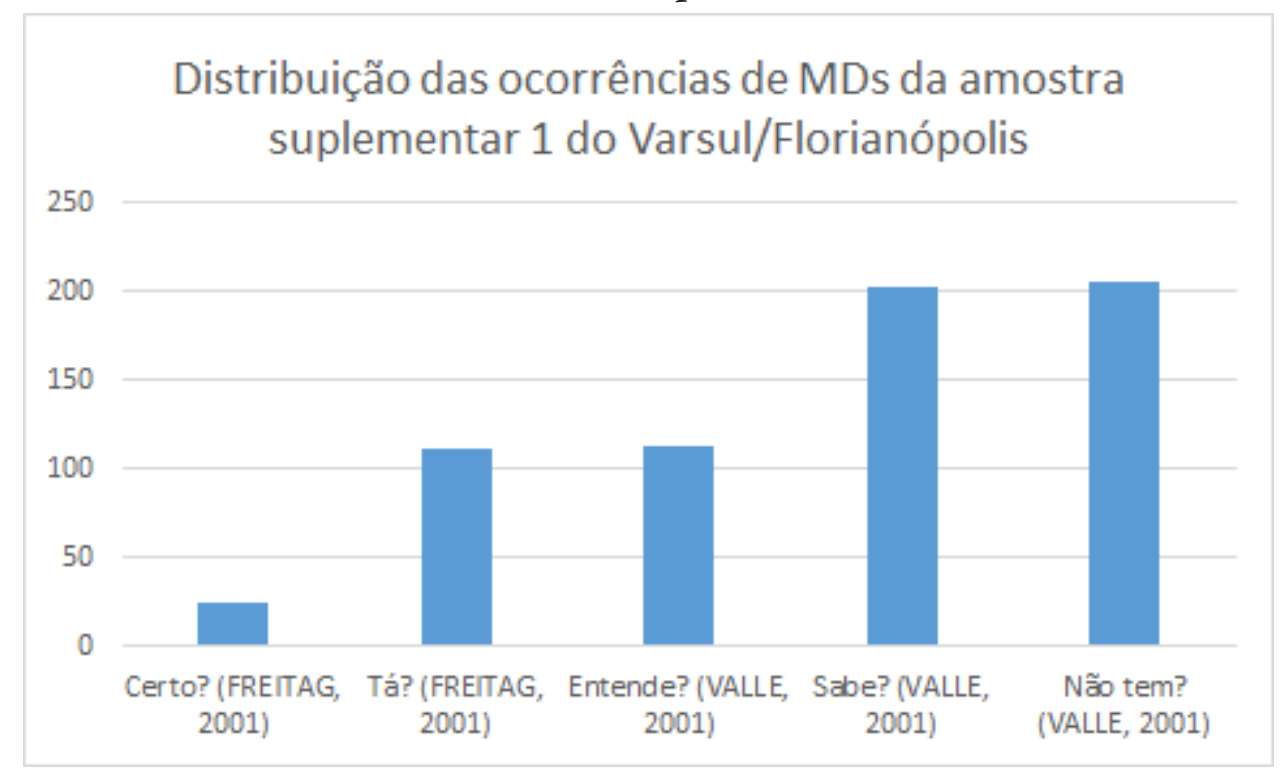

Fonte: Elaboração das autoras (2020).

As duas pesquisas controlaram as variáveis sociais idade (com três faixas), sexo e escolaridade, cujos resultados gerais reunimos abaixo.

Quanto à variável idade, Silva e Macedo (1996) observaram diferenças sutis entre as três faixas etárias consideradas em sua análise. Os resultados obtidos por Freitag (2001) e Valle (2001) indicam que o aumento da faixa etária propicia a variação dos MDs. Contudo, Freitag (2001) observou que, quanto mais jovens os falantes, menos possibilidade de variação, ou seja, na faixa etária de 15 a 25 anos, o uso de tá? é categórico. 
Isso significa que o processo de mudança pode estar em estágio mais avançado porque os falantes mais jovens podem não estar aprendendo a variante certo? Valle (2001), por sua vez, identificou uma escala decrescente de uso dos RADs que vai dos mais jovens aos mais velhos. Uma possibilidade de interpretação, segundo a autora, seria correlacionar essa escalaridade a fatores de maturação, ou seja, os mais jovens podem estar fazendo maior uso dos RADs, por se sentirem ainda inseguros sobre suas opiniões em determinados assuntos. Ressalve-se que gradação etária dos informantes controlada nessa amostra já pode sinalizar uma tendência significativa de mudança em tempo aparente.

Quanto à variável sexo, Silva e Macedo (1996) constataram que, de modo geral, os RADs são usados de modo equilibrado entre homens e mulheres, não havendo nenhuma interferência dessa variável na distribuição desses itens. De um lado, os resultados de Valle (2001) demonstraram que não há diferenças entre homens e mulheres no uso dos RADs em geral, conforme observado por Silva e Macedo (1996), de outro, Freitag (2001) observou que uso variável de tá? e certo? foi mais frequente em falantes do sexo masculino.

Quanto à variável escolaridade, Silva e Macedo (1996) observaram que, de modo geral, o uso dos RADs não apresentou diferenças de acordo com o aumento da escolaridade. Essa disparidade entre os RADs foi observada por Martelotta e Leitão (1998), eles verificaram que entendeu? é mais utilizado entre os níveis de escolaridade mais alta, sendo que sabe?, por outro lado, não segue esta tendência. Os resultados de Freitag (2001) confirmaram que o uso variável de tá? e certo? está correlacionado com o aumento do tempo de escolarização. Contudo, os resultados de Valle (2001) demonstraram justamente o contrário, o maior uso dos RADs entre os menos escolarizados.

$\mathrm{O}$ que conseguimos resumir até aqui a respeito do comportamento dos MDs certo?, tá?, sabe?, não tem? e entende? na amostra suplementar 1 do VARSUL/Florianópolis? (i) os mais velhos variam mais o uso de tá?, certo?, sabe?, não tem? e entende?, e os mais jovens empregam de modo categórico o emprego de tá?; (ii) não há diferenças relativas ao sexo no uso dos RADs, ao passo que os homens usam mais tá? e certo?; (iii) os mais escolarizados usam mais tá? e certo?, enquanto que os menos escolarizados empregam mais os RADs.

Passamos aos resultados da amostra suplementar 2 do VARSUL/Florianópolis, que conta com 44 entrevistas de florianopolitanos. As pesquisas que investigaram essa amostra suplementar localizaram o total de 225 MDs (ROST, 2002; ROST SNICHELOTTO, 2009). Vejamos a distribuição da frequência dos MDs no gráfico abaixo: 
Gráfico 3 - Distribuição das ocorrências de MDs da amostra suplementar do Varsul/ Florianópolis 2.

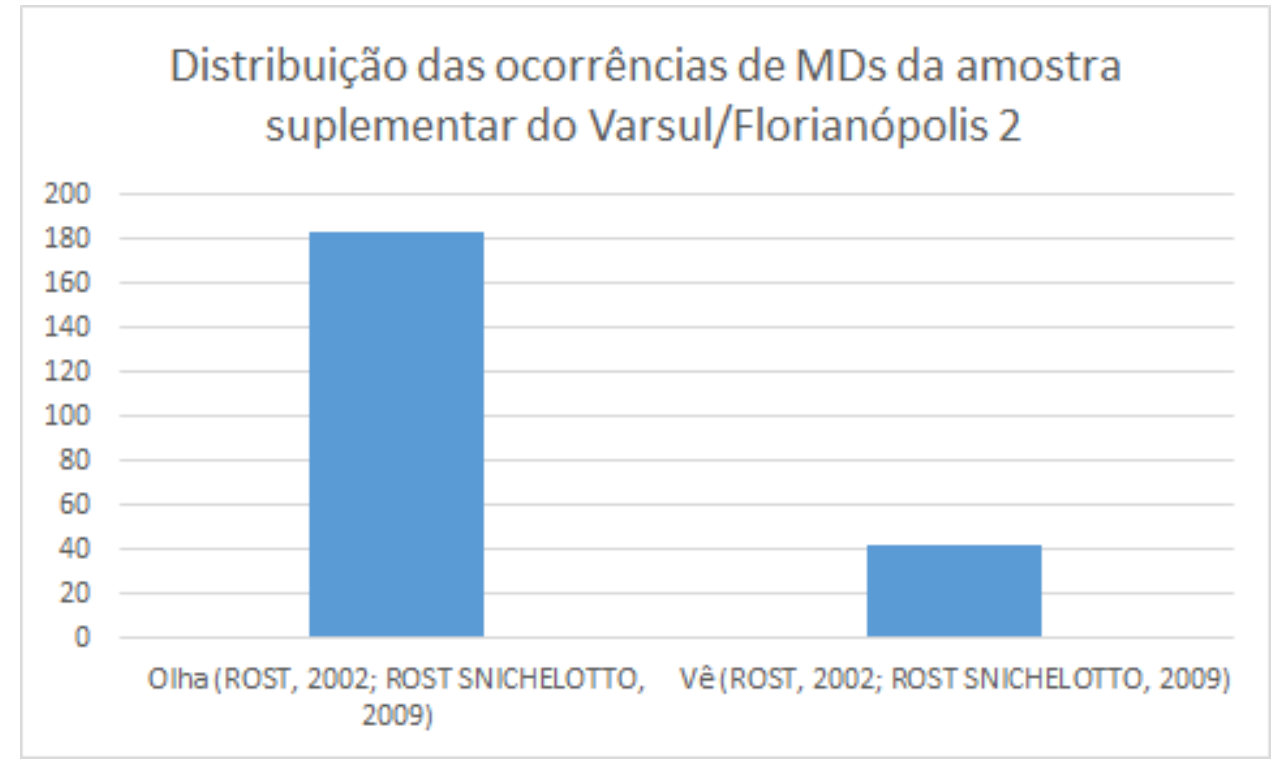

Fonte: Elaboração das autoras (2020).

As duas pesquisas controlaram as variáveis sociais idade (com três faixas), sexo e escolaridade (com quatros níveis), cujos resultados gerais reunimos abaixo.

Assim como no levantamento dos dados da amostra base do VARSUL/ Florianópolis, esse resultado confirma o predomínio de olha sobre vê.

Quanto à variável idade, esperava-se uma distribuição crescente de frequência de uso dos MDs à medida que a faixa etária diminuísse, de modo que os jovens utilizariam mais esses MDs que os adultos, que, por sua vez, fariam mais uso desses itens que os mais velhos. A distribuição de frequência ficaria assim delineada: jovens > faixa intermediária > mais velhos. Embora pareça não haver avaliação social aparente associada a esses MDs, não foi descartada a possibilidade de haver alguma relação com o fator mercado de trabalho. Os resultados revelaram que é na faixa de 25 a 49 anos que se concentra o maior uso do MD vê na capital catarinense, enquanto que o MD olha é altamente favorecido entre os informantes da faixa etária jovem e fortemente inibido na faixa intermediária. Esses resultados reforçam a hipótese de Traugott e Dasher (2005), ou seja, muitas mudanças são iniciadas pelos adultos jovens, principalmente transmitidas pela força da autoridade educacional, jurídica, política ou religiosa, não pelas crianças, devido à falta de maturidade para compreender complexas inferências envolvidas e funções discursivas da estrutura textual (ROST, 2002; ROST SNICHELOTTO, 2009).

Quanto à variável sexo, curiosamente, com a entrada de jovens e universitários na 
amostra suplementar 2 do VARSUL/Florianópolis, houve perda da significância estatística constatada no levantamento dos dados da amostra base, neutralizando-se a diferença entre homens e mulheres quanto ao uso desses MDs.

Quanto à variável escolaridade, havia a expectativa de que as diferenças nos níveis de escolarização poderiam influenciar os usos de uma ou outra variante. Essa hipótese se baseia em estudos variacionistas que apontam os efeitos interessantes dessa variável sobre o uso de formas discursivas no PB. Citam-se, por exemplo, as pesquisas de Martins (2003) e Görski e Freitag (2006), com amostras do VARSUL. Contudo, a exemplo dos resultados encontrados por Silva e Macedo (1996), a entrada de informantes universitários na amostra não se revelou significativa para os resultados do comportamento variável de olha e vê (ROST, 2002; ROST SNICHELOTTO, 2009).

$\mathrm{O}$ que conseguimos resumir até aqui a respeito dos resultados do comportamento dos MDs olha e vê na amostra suplementar 2 do VARSUL? (i) os mais jovens favorecem o uso de olha e os informantes de 25 a 49 anos preferem vế; (ii) homens e mulheres revelam comportamento semelhante no uso de olha e vê; (iii) a escolaridade não se revelou significativa para o uso de olha e vê.

Passamos aos resultados da amostra suplementar 3 do VARSUL/Florianópolis, que conta com 30 entrevistas de florianopolitanos da comunidade da Barra da Lagoa. Valle (2014) localizou o total de 1610 RADs cujo volume mostrou-se muito superior ao das pesquisas anteriores sobre itens discursivos. Vejamos a distribuição da frequência dos MDs no gráfico abaixo:

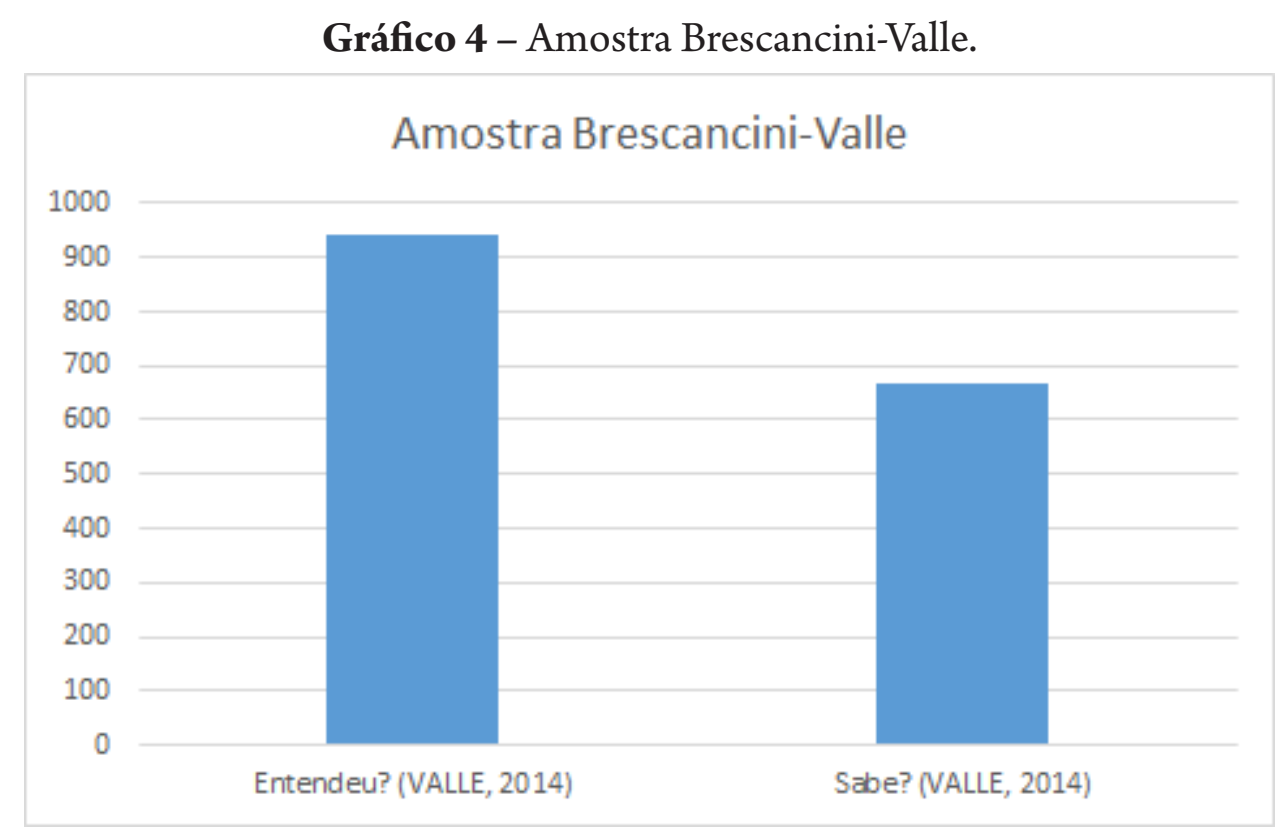

Fonte: Elaboração das autoras (2020). 
Valle (2014) controlou as variáveis sociais idade (com três faixas), sexo e escolaridade (com 10 níveis), porém, alerta que a composição de células sociais foi prejudicada pela própria configuração da amostra.

Assim, de modo geral, reservadas as especificidades de cada RAD e a composição da amostra, quanto à variável idade, foi observada uma nítida preferência por sabe? entre os mais jovens, enquanto entre os de meia idade predomina o uso de entendeu?, principalmente da forma entendesse?, o que pode estar indicando uma distribuição geracional para os RADs,

Quanto à variável sexo, os homens usam mais RADs do que mulheres, mas as mulheres empregam mais sabe? do que os homens que usam mais entende?

Quanto às variáveis idade e escolaridade, Valle (2014) supõe que os resultados estejam apresentando um comportamento espelhado, pois, na amostra investigada, mais velhos sempre têm menos escolarização, enquanto jovens sempre possuem mais escolarização. A diversificação de escolarização ocorre apenas entre os informantes da faixa intermediária.

O que conseguimos resumir até aqui a respeito dos resultados do comportamento dos RADs na amostra suplementar 3 do VARSUL? Os resultados gerais do controle das células sociais, segundo Valle (2014, p. 320), demonstram que os informantes mais jovens usam mais RADs e o uso diminui em um gradiente até os mais velhos; os homens usam mais RADs do que mulheres; e quanto mais alta a escolarização, mais alto é o uso dos RADs.

\section{Considerações finais}

Após 20 anos, amadurecemos pessoal e profissionalmente. Esta compilação de dissertações e teses teve o intuito de fazer um apanhado das pesquisas que têm sido efetuadas sobre elementos discursivos a partir de dados do VARSUL de Florianópolis, segundo os projetos de pesquisa da professora Edair Görski. Com esse apanhado, buscamos descrever esses elementos linguísticos e os fatores sociais que possam influenciar no seu uso. Cabe o destaque que esse conjunto de trabalhos orientados pela Edair resultaram em dezenas de materiais bibliográficos e impulsionaram outras dezenas de publicações e apresentações dos resultados em eventos nacionais e internacionais.

A primeira questão que colocamos inicialmente foi: $\mathrm{O}$ que os estudos sobre MDs têm a dizer, em especial, sobre a fala florianopolitana?

Vimos que as pesquisas até este momento se centraram mais na descrição da mul- 
tifuncionalidade dos MDs derivados de verbos do que dos MDs derivados de adjetivos e advérbios, o que pode sinalizar a predisposição de formas verbais a evoluírem para a conformação do processo discursivo de estabelecimento de contato e colaboração mútua entre os interlocutores (RISSO; SILVA; URBANO, 2006, p. 423). Também vimos que o levantamento da frequência de uso dos itens em diferentes contextos de uso permitiu observar tanto situações de variação como contextos de restrição de uso de cada forma investigada.

A segunda questão que colocamos foi: O que o controle de fatores extralinguísticos tem a revelar a respeito do uso dos MDs em Florianópolis?

Os sete trabalhos aqui reunidos analisaram dois bairros da capital catarinense, mas apenas Valle (2014) coletou dados da fala da comunidade da Barra da Lagoa, bairro situado a 20 quilômetros da área central da cidade. Cabe também a ressalva de que centramos este artigo na descrição dos resultados relativos à fala, mas apenas Rost Snichelotto (2009) efetuou uma análise diacrônica dos dados, representada por escritos teatrais de catarinenses dos séculos XIX e XX.

De modo geral, o controle dos aspectos sociais das quatro amostras do VARSUL/ Florianópolis revelou que:

a) na amostra base do VARSUL/Florianópolis, (i) os mais jovens usam mais olha e $v \hat{e}$, e os mais velhos empregam mais quer dizer, bom e bem; (ii) os homens usam mais olha, $v \hat{e}$, bom e bem; homens e mulheres demonstram pouca diferença em relação ao emprego de quer dizer; e (iii) os mais escolarizados usam mais quer dizer, bom e bem; ambos níveis de escolarização empregam de modo equilibrado olha e $v \hat{e}$;

b) na amostra suplementar 1 do VARSUL/Florianópolis, (i) os mais velhos variam mais o uso de tá?, certo?, sabe?, não tem? e entende?; os mais jovens tendem a usar mais sabe?, não tem? e entende? e a empregar de modo categórico tá?; (ii) não há diferenças relativas ao sexo no uso dos RADs, ao passo que os homens usam mais tá? e certo?; e (iii) os mais escolarizados usam mais tá? e certo?, enquanto que os menos escolarizados empregam mais os RADs;

c) na amostra suplementar 2 do VARSUL/Florianópolis, (i) os jovens favorecem o uso de olha e os informantes de 25 a 49 anos preferem $v \hat{e}$; (ii) homens e mulheres revelam comportamento semelhante no uso de olha e vê; (iii) a escolaridade não se revelou significativa para o uso de olha e vê;

d) na amostra suplementar 3 do VARSUL/Florianópolis, (i) os mais jovens usam mais RADs e o uso diminui em um gradiente até os mais velhos; (ii) homens usam mais 
RADs do que mulheres; (iii) quanto mais alta a escolarização, mais alto é o uso dos RADs.

Vimos também a importância do cuidado com a generalização de amostras de Florianópolis em razão das diferenças na composição de células sociais que têm configurações distintas e das áreas geográficas coletadas (dois bairros da capital).

Por fim, o volume de MDs levantados nas quatro amostras diversificadas do VARSUL permitiu a descrição do seu uso na cidade de Florianópolis, mas proporciona também uma dimensão mais geral do comportamento dos MDs no português do Brasil.

\section{Referências}

BAGNO, M. Gramática Pedagógica do português brasileiro. São Paulo: Parábola Editorial, 2012.

BASÍLIO, M. Flutuação categorial de base adjetiva no português falado. ILARI, R. (Org.). Gramática do português falado. 4. ed. rev. Campinas, SP: Unicamp, 2002. p. 75-90. (Série Pesquisas, v. II: Níveis de análise linguística)

BISOL, L. VARSUL: amostra, coleta e transcrição. ZILLES, A. M. S. (Org.). Estudos de variação linguística no Brasil e no Cone Sul. Porto Alegre: Editora da UFRGS, 2005. p. 151153.

BRESCANCINI, C. R. A fricativa palato-alveolar e sua complexidade: uma regra variável. 2002. 364 f. Tese (Doutorado em Linguística e Letras) - Pontifícia Universidade Católica do Rio Grande do Sul, Porto Alegre, 2002.

BYBEE, J. Language, usage and cognition. Cambridge: Cambridge University Press, 2010.

CASTILHO, A. T. de. Para o estudo das unidades discursivas no português falado. CASTILHO, A. T. de. (Org.). Português culto falado no Brasil. Campinas: Ed. da Unicamp, 1989. p. 249-279.

CONSTANTE, S. O parece que está se gramaticalizando, parece. Universidade Federal de Santa Catarina, Departamento de Língua e Literaturas Vernáculas, 2001. [Relatório de Iniciação Científica].

COSTA, I. B. O banco de dados linguísticos VARSUL e seus usuários. ZILLES, A. M. S. (Org.). Estudos de variação linguística no Brasil e no Cone Sul. Porto Alegre: Editora da UFRGS, 2005. p. 165-170.

COULTHARD, M. Linguagem e sexo. São Paulo: Ática, 1991.

DAL MAGO, D. Quer dizer: percurso de mudança via gramaticalização e discursivização. 2001. Dissertação (Mestrado em Linguística) - Universidade Federal de Santa Catarina, Programa de Pós-Graduação em Linguística, Florianópolis, 2001.

DUARTE, S. L. Funções discursivas de JÁ e AGORA na fala de Chapecó. 1997. Iniciação Científica - Universidade Federal de Santa Catarina, Conselho Nacional de Desenvolvimento Científico e Tecnológico. Orientador: Edair Maria Görski. 
DUARTE, S. L. Um estudo dos advérbios como marcadores discursivos na fala de Florianópolis. 1996. Iniciação Científica - Universidade Federal de Santa Catarina, Conselho Nacional de Desenvolvimento Científico e Tecnológico. Orientador: Edair Maria Görski.

ECKERT, P. Three waves of variation study: The emergence of meaning in the study of variation. Annual Review of Anthropology, n. 41, p. 87-100, jun. 2012.

FRASER, B. What are discourse markers?. Journal of Pragmatics, v. 31, 1999, p. 931-952.

FREITAG; R M. K. O papel de frequência de uso na gramaticalização de acho (que) e parece (que) marcadores de dúvida na fala de Florianópolis, Veredas, v. 7, n.1-2, p. 113132, jul./dez. 2003.

FREITAG, R. M K. O uso de Tá? e Certo? na fala de Santa Catarina. Working Papers em Linguística, Florianópolis, v. 5, n. 1, p. 25-41, jan. 2001. Disponível em: https://periodicos. ufsc.br/index.php/workingpapers/article/view/4786. Acesso em: 13 jul. 2020.

FREITAG, R. M. K. Os marcadores discursivos 'tá?' e 'certo?' na fala de Florianópolis. Relatório final de pesquisa do Programa Interinstitucional de Bolsas de Iniciação Científica PIBIC/CNPq/UFSC biênio 1998-1999. Florianópolis, Universidade Federal de Santa Catarina, 1999.

GASPARINI, M. ASSIM se fala, ASSIM se escreve. 2001. Dissertação (Mestrado em Linguística) - Universidade Federal de Santa Catarina, Florianópolis, 2001.

GÓES, S. Funções discursivas de AÍ na fala de Florianópolis. 1998. Iniciação Científica - Universidade Federal de Santa Catarina, Conselho Nacional de Desenvolvimento Científico e Tecnológico. Orientador: Edair Maria Görski.

GÖRSKI, E. M. A questão do continuum na interface variação/gramaticalização. 70 Encontro do Celsul. Palotti: Pelotas, 2006.

GÖRSKI, E. M. Espectro funcional de bem e bom no português falado: instâncias de gramaticalização. Revista da ABRALIN, v. 19, n. 3, p. 131-158, 17 dez. 2020.

GÖRSKI, E. M. et al. Gramaticalização/discursivização de itens de base verbal: funções e formas concorrentes. Estudos Linguísticos. Vol. XXXI. São Paulo, 2002.

GÖRSKI, E. M. Fenômenos discursivos: resultados de análises variacionistas como indícios de gramaticalização. RONCARATI, C.; ABRAÇADO, J. (Org.). Português brasileiro: contato linguístico, heterogeneidade e história. Rio de Janeiro: 7 Letras, 2003, p. 106-122.

GÖRSKI, E. M.; FREITAG, R. M. K. Marcação e comportamento sociolinguístico de marcadores discursivos interacionais na fala de Florianópolis. VANDRESEN, P. (Org.). Variação, mudança e contato linguístico no português da região sul. Pelotas: EDUCAT, 2006, p. 28-50.

MARCUSCHI, L. A. Marcadores conversacionais do português brasileiro: formas, funções e definições. CASTILHO, A. (Org.). Português culto falado no Brasil. Campinas: Ed. da UNICAMP, 1989. p. 281-322. 
MARTELOTTA, M. E.; LEITÃO, M. Igualdades e diferenças nos marcadores discursivos sabe? e entendeu? Artigos produzidos pelo Grupo Discurso \& Gramática sobre gramaticalização no português do Brasil. UFRJ, Rio de Janeiro, 1998. Mimeo.

MARTELOTTA, M. e LEITÃO, M. Discursivização do verbo saber. MARTELOTTA, Mario Eduardo; VOTRE, Sebastião Josué; CEZARIO, Maria Maura. (Org.) Gramaticalização no português do Brasil: uma abordagem funcional. Rio de Janeiro: Tempo Brasileiro/UFRJ, 1996.

MARTELOTTA, M. E.; VOTRE, S.; CEZARIO, M. M. (Org.). Gramaticalização no português do Brasil: uma abordagem funcional. Rio de Janeiro: Tempo Brasileiro, 1996.

MARTINS, L. T. Bom e bem e suas multifunções na fala da região sul do Brasil. 2003. 96 f. Dissertação (Mestrado) - Universidade Federal de Santa Catarina, Centro de Comunicação e Expressão, Programa de Pós-Graduação em Linguística, 2003.

MASCHLER, Y.; SCHIFFRIN, D. Discourse markers: language, meaning, and context. TANNEN, D.; HAMILTON, H. E.; SCHIFFRIN, D. The handbook of discourse analysis. Hoboken, EUA: Wiley-Blackwell, 2015.

MONGUILHOTT, I. O. S. Estudo sincrônico e diacrônico da concordância verbal de terceira pessoa do plural no PB e no PE. 2009. 228 f. Tese (Doutorado) - Universidade Federal de Santa Catarina, Centro de Comunicação e Expressão, Programa de Pós-Graduação em Linguística, Florianópolis, 2009. Disponível em: http://www.tede.ufsc.br/teses/ PLLG0430-T.pdf\&g. Acesso em: 12 ago. 2020.

NARO, A. J. Modelos quantitativos e tratamento estatístico. MOLLICA, M. C. (Org.). Introdução à sociolinguística variacionista. Rio de Janeiro, UFRJ, 1992.

NARO, A. J. Variação e funcionalidade. Revista Estudos Linguísticos, Belo Horizonte, v. 7, n. 2, 1998.

NARO, A. J.; BRAGA, M. L. A interface sociolinguística/gramaticalização. Gragoatá Revista do Programa de Pós-Graduação em Letras, Niterói, n. 9, 2º semestre, 2000.

OLIVEIRA, D. M. Tudo: multifuncionalidade e definitude. 2006. Dissertação (Mestrado em Linguística) - Universidade Federal de Santa Catarina, Florianópolis, 2006.

PAIVA, M. C.; DUARTE, M. E. (Orgs.). Mudança linguística em tempo real. Rio de Janeiro: Contra Capa Livraria, 2003.

PINTZUK, S. Varbrul programs. 1988. [mimeo]

PONS BORDERÍA, S. Oye y mira o los límites de la conexión. ZORRAQUINO, M. A.M. et al. Los marcadores del discurso: teorı y análisis. Madrid: Arco Libros, 1998. p. 213-228.

RISSO, M. S.; SILVA, G. M. O.; URBANO, H. Marcadores discursivos basicamente sequenciadores. JUBRAN, C. C. A. S.; KOCH, I. G. V. (Org.). Gramática do português culto falado no Brasil. Campinas: Ed. da Unicamp, 2006. v.1. p. 427-496. (Construção do texto falado). 
RISSO, M. S.; SILVA, G. M. O.; URBANO, H. Marcadores discursivos: traços definidores. KOCH, I. G. V. (Org.). Gramática do português falado. Campinas: Ed. da Unicamp, 1996. v. 4.p. 21-94.

RISSO, M. S. Aspectos textuais-interativos dos marcadores discursivos de abertura Bom, Bem, Olha, Ah, no português culto falado. NEVES, M. H. M. (Org.). Gramática do português falado. Campinas, SP: Editora da UNICAMP, 1999. Vol. VII.

ROST SNICHELOTTO, C. A. Olha e vê: caminhos que se entrecruzam. 2009. 408 f. Tese (Doutorado em Linguística) - Programa de Pós-Graduação em Linguística, Universidade Federal de Santa Catarina, Florianópolis, 2009.

ROST SNICHELOTTO, C. A.; GORSKI, E. M. (Inter)subjetivização de marcadores discursivos de base verbal: instâncias de gramaticalização. Alfa, rev. lingüíst. (São José Rio Preto), São Paulo, v. 55, n. 2, p. 423-455, dec. 2011. Disponível em: http://www.scielo. br/scielo.php?script=sci_arttext\&pid=S1981-57942011000200004\&lng=en\&nrm=iso. Acesso em: 25 abr. 2021.

ROST, C. A. Olha e veja: multifuncionalidade e variação. 2002. 158 f. Dissertação (Mestrado em Linguística) - Programa de Pós-Graduação em Linguística, Universidade Federal de Santa Catarina, Florianópolis, 2002.

SANKOFF, D. Variable rules. AMMON, U.; DITMAR, N.; MATTEIR, K.. (Eds.). Sociolinguistics: an international handbook of the science of language and society. New York: Walter de Gruyter, 1988.

SANKOFF, D.; TAGLIAMONTE, S. A.; SMITH, E. Goldvarb X: A variable rule application for Macintosh and Windows. Toronto: Department of Linguistics; Ottawa: Department of Mathematics, 2005. Disponível em: http://individual.utoronto.ca/ tagliamonte/goldvarb.htm. Acesso em: 11 fev. 2014.

SCHIFFRIN, D. Discourse markers. Cambridge: Cambridge University Press, 1987.

SCHIFFRIN, D. Discourse markers: language, meaning and context. SCHIFFRIN, D.; TANNEN, D.; HAMILTON, H. E. (Eds.). The handbook of discourse analysis. Malden, MA: Blackwell, 2003. p. 54-74.

SILVA, G. M.; MACEDO, A. Análise sociolinguística de alguns marcadores conversacionais. MACEDO, A.; RONCARATI, C.; MOLLICA, M. C. (Org.). Variação e discurso. Rio de Janeiro: Tempo Brasileiro, 1996. p. 11-50.

TAVARES, M. A.A gramaticalização de E, AÍ, DAÍ e ENTÃO: estratificação/variação e mudança no domínio funcional da sequenciação retroativo-propulsora de informações - um estudo sociofuncionalista. 2003. Tese (Doutorado em Linguística) - Programa de Pós-graduação em Linguística, Universidade Federal de Santa Catarina, Florianópolis, 2003.

TAVARES, M. A. Funções discursivas do ENTÃO na fala de Florianópolis. 1997. 0 f. Iniciação Científica - Universidade Federal de Santa Catarina, Conselho Nacional de Desenvolvimento Científico e Tecnológico. Orientador: Edair Maria Görski. 
TAVARES, M. A. Um estudo dos advérbios como marcadores discursivos na fala de Florianópolis. 1996. 0 f. Iniciação Científica - Universidade Federal de Santa Catarina, Conselho Nacional de Desenvolvimento Científico e Tecnológico. Orientador: Edair Maria Görski.

TAVARES, M. A. Um estudo variacionista de aí, daí, então e e como conectores sequenciadores retroativo-propulsores na fala de Florianópolis. 1999. 175 f. Dissertação (Mestrado) - Universidade Federal de Santa Catarina, Centro de Comunicação e Expressão, Florianópolis, 1999.

TAVARES, M. A.; GÖRSKI, E. M. Variação e sociofuncionalismo. MARTINS, Marco A.; ABRAÇADO, J. (Org.). Mapeamento sociolinguístico do português brasileiro. São Paulo: Contexto, 2015. p. 249-270.

TAVARES, M. A.; GÖRSKI, E. M. Bases teórico-metodológicas para uma interface sociofuncionalista. Texto apresentado e discutido no XXVII Encontro Nacional da Anpoll - ENANPOLL, Rio de Janeiro-RJ, 10 a 13 de julho de 2012.

TRAUGOTT, E. C. The development of "digressive" discourse-topic shift markers in English. Journal of Pragmatics, v. 156, p. 121-135, 2020.

TRAUGOTT, E. C.; DASHER, R. B. The development of modal verbs. TRAUGOTT, E. C.; DASHER, R. B. Regularity in semantic change. Cambridge: Cambridge U.P., 2005, p. 105-151.

URBANO, H. Marcadores conversacionais. PRETI, D. (Org.). Análise de textos orais. 3. ed. v. 1. São Paulo: Humanitas, 1997. p. 81-101.

VALLE, C. R. M. Funções discursivas do advérbio ASSIM na fala de Chapecó. 1998. 0 f. Iniciação Científica - Universidade Federal de Santa Catarina, Conselho Nacional de Desenvolvimento Científico e Tecnológico. Orientador: Edair Maria Görski.

VALLE, C. R. M. Multifuncionalidade, mudança e variação de marcadores discursivos derivados de verbos cognitivos: forças semântico-pragmáticas, estilísticas e identitárias em competição. 2014. 415 p. Tese (Doutorado) - Universidade Federal de Santa Catarina, Centro de Comunicação e Expressão, Programa de Pós-Graduação em Linguística, Florianópolis, 2014.

VALLE, C. R. M. Os marcadores discursivos SABE? e ENTENDE? na fala dos florianopolitanos. 1999. 0 f. Iniciação Científica - Universidade Federal de Santa Catarina, Conselho Nacional de Desenvolvimento Científico e Tecnológico. Orientador: Edair Maria Görski.

VALLE, C. R. M. Sabe? Não tem? Entende?: itens de origem verbal em variação como requisitos de apoio discursivo. 2001. 170 f. Dissertação (Mestrado) - Universidade Federal de Santa Catarina, Centro de Comunicação e Expressão, Programa de PósGraduação em Linguística. Disponível em: http://www.tede.ufsc.br/teses/PLLG0284. pdf. Acesso em: 21 jul. 2020. 
VALLE, C. R. M.; GÖRSKI, E. M. Por um tratamento multidimensional da variação estilística na entrevista sociolinguística. GÖRSKI, E. M.; COELHO, I. L.; NUNES DE SOUZA, C. M. (Org.). Variação estilística - reflexões teórico-metodológicas e propostas de análise. Coleção Linguística. V. 3. Florianópolis: Insular, 2014. p. 93-121.

VANDRESEN, P. O banco de dados VARSUL: do sonho à realidade. ZILLES, A. M. S. (Org.). Estudos de variação linguística no Brasil e no Cone Sul. Porto Alegre: Editora da URGS, 2005, p. 145-149.

VANDRESEN, P.; COELHO, I. L. Formação e políticas de disponibilização do Banco VARSUL. GONÇALVES, C. A.; ALMEIDA, M. L. L. (Org.) Lingua Portuguesa: identidade, difusão e variabilidade. Rio de Janeiro: AILP/UFRJ, 2008. p. 75-86.

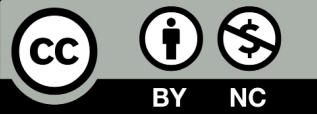

Data de submissão: 25/02/2020

Data de aceite: $28 / 05 / 2020$ 